\title{
Clubfoot management in the Middle East: a survey-based review
}

\author{
Ismat Ghanem $^{1,2}$, Maroun Rizkallah $^{1 \wedge}$ \\ ${ }^{1}$ Faculty of Medicine, Saint-Joseph University, Beirut, Lebanon; ${ }^{2}$ Hôtel-Dieu de France University Hospital, Saint-Joseph University, Beirut, \\ Lebanon \\ Contributions: (I) Conception and design: Both authors; (II) Administrative support: I Ghanem; (III) Provision of study materials or patients: Both \\ authors; (IV) Collection and assembly of data: Both authors; (V) Data analysis and interpretation: Both authors; (VI) Manuscript writing: Both \\ authors; (VII) Final approval of manuscript: Both authors. \\ Correspondence to: Maroun Rizkallah, MD. Faculty of Medicine, Saint Joseph University, Beirut, Lebanon; Department of Orthopedic Surgery, Hôtel- \\ Dieu de France Hospital, Saint Joseph University, Alfred Naccache street, Achrafieh, Beirut, Lebanon. Email: maroun.rizkallah@gmail.com.
}

\begin{abstract}
Clubfoot is the most frequent congenital deformity involving the foot. Little is known about the management of this disease in the Middle East as sparse data is available in the literature. Through the last 5 decades, congenital clubfoot management in the Middle East went from manipulation through Kite's technique in the late seventies, to early primary surgical intervention in the late eighties and early nineties of the previous century, and then back to manipulation with Ponseti's technique and the French functional technique in the late nineties, with the latter falling out of favor with time. This is comparable to the evolution of management witnessed in the United States and in Europe, with 10 to 15 years of delay. The delay is getting shorter with time due to the easier access to published scientific data and the increasing number of fellows from Middle East travelling to referral centers in Europe and the USA. A survey was performed among pediatric orthopedic surgeons in the Middle East to assess their approach to clubfoot management. This is the first survey of its kind in the region. It showed a wide adoption (97.1\%) of the Ponseti's technique with serial manipulation and casting, Achilles tenotomy followed by abduction bracing. Divergent practices were found concerning the upper age limit for Ponseti treatment and the setting of the Achilles tenotomy. Nevertheless, these subjects are still a matter of debate in the literature and international conferences. All in all, pediatric orthopedic surgeons in the Middle East are offering their patients the gold standard of care. However, lot of work is to be done in raising awareness for this disease in the community, and among our colleagues as prenatal screening for clubfoot in the Middle East is practically nonexistent.
\end{abstract}

Keywords: Clubfoot management; Middle East; survey; Ponseti; French functional method

Submitted Jan 04, 2021. Accepted for publication Mar 04, 2021.

doi: $10.21037 / \mathrm{atm}-21-33$

View this article at: http://dx.doi.org/10.21037/atm-21-33

\section{Introduction}

Clubfoot, or congenital talipes equinovarus, is the most frequently encountered congenital deformity involving the foot (1-3). It is a complex tridimensional deformity concerning hindfoot, midfoot and forefoot $(1,2,4)$. This deformity consists of four components: equinus, hindfoot varus, forefoot adductus, and midfoot cavus $(1,4,5)$. Its exact etiology remains debated and general consensus favors contribution of multiple genetic and environmental factors (6-8). Nowadays, clubfoot is identifiable during routine intrauterine ultrasound, mainly in the second trimester of the antenatal period $(5,9)$. The diagnosis is confirmed at birth through clinical evaluation as radiographs are of little benefit $(1,5)$.

Clubfoot was known in antiquity and oldest proofs come from the Middle East region, mainly from archeological

$\wedge$ ORCID: 0000-0003-2592-7841. 
studies in ancient Egyptian tombs (10). Egyptian Pharaoh Siptah who lived in the 12th century B.C. had a left clubfoot. Other drawings from Egyptian temples showed adult-males with bilateral clubfeet showing that adulthood was reached back to those times without correction of foot deformity (10). However, even in antiquity, attempts were made to make the deformed foot plantigrade (11-13). The first written description comes from Hippocrates from Kos in 400 B.C. He described methods of serial manipulations followed by application of strong bandages to maintain correction and states clearly that correction should start as early as possible (10-13). Through the following centuries and until renaissance, they were barber-surgeons, charlatans and bonesetters who took care of this deformity $(12,13)$. Even through the last century, orthopedic surgeons struggled to identify the best and reproducible method for the treatment of the congenital clubfoot deformity (14-16). This struggle has lessened only recently in the last decades when Ponseti's method of manipulation and serial casting with Achilles tendon tenotomy followed by abduction bracing became unanimously the gold standard treatment method for congenital clubfoot nearly around the world (5,17-20).

Even though clubfoot excited and was reported since antiquity in the middle east, there is only sparse data in the literature concerning clubfoot management in this region (21). This article will describe the evolution of clubfoot management in the past 5 decades in the Middle East and will present the results of the first survey of its kind evaluating the actual management of clubfoot by pediatric orthopedic surgeons (POS) in the Middle East. We present the following article in accordance with the SURGE reporting checklist (available at http://dx.doi.org/10.21037/atm-21-33).

\section{Evolution of clubfoot management in the Middle East, particularly in Lebanon through the last 5 decades}

Little data concerning clubfoot management in the Middle East is available in the medical literature. Three studies evaluating incidence of clubfoot among other congenital malformations in Lebanon, Iraq, and Egypt where used by Smythe et al. to determine birth prevalence of congenital talipes equinovarus in the eastern Mediterranean region (22-25). It was found to occur in $1.19(0.98-1.40)$ per 1,000 livebirths in this region (25). This is comparable to the commonly reported birth prevalence of congenital clubfoot in the literature $(7,26)$.

Data about management of clubfoot in the Middle East through the past five centuries is based on the experience of the authors who witnessed the evolving approaches as medical students, orthopedic surgery residents, international fellows, and as specialized surgeons.

During the seventies and early eighties of the last century, Kite's method of functional treatment was the main adopted approach for clubfoot treatment in Lebanon and the Middle Eastern countries. Kite's method was appealing as it was the first non-surgical treatment to receive international consensus $(5,13)$. Since it was regularly presented in scientific meetings dealing with congenital clubfoot, this technique was taught to orthopedic surgeons practicing in the referral hospitals of the big cities and was therefore imported to Lebanon. Its main contribution was the establishment of the principle that each deformity in the clubfoot should be addressed differently following a rigorous order $(12,13)$. First the forefoot adduction was manipulated using the calcaneocuboid joint as a fulcrum, then the hindfoot varus was addressed through a simple eversion of the calcaneus. The ankle equinus correction followed and finally the midfoot cavus deformity was addressed (27-29). This technique was based on gentle manipulation as opposed to forceful corrections that were adopted before, however this technique was lengthy and patients were casted sometimes for up to 2 years (27-29). The success rates reported by Kite was not reproducible as failure rates reached $50 \%$ and more in series around the world $(30,31)$.

These flaws in Kite's technique together with the quick development of safe anesthesia technics in newborns in the Middle East and the worldwide surge of surgical techniques involving only soft tissues release made surgeries for clubfoot popular in Lebanon and the region in late eighties and early nineties of the previous century. Surgery was attractive because it brings a onetime definitive effective solution to the deformity and spares the children and their parents' lengthy manipulations that may sometimes lead to suboptimal results (32). More, surgery is performed between 6 months and 1 year of age, making it advantageous to manipulations technique that should start immediately after birth. This is of paramount importance in the Middle East region where awareness about clubfoot as a curable deformity that needs immediate and prompt care and intervention was lacking in that period (33). It was the McKay surgical approach rather than the Turco technique that was performed in Lebanon (34). However, local experience went together with international scientific reports and showed immediate complications with surgeries 
such as incomplete corrections, overcorrections and irreversible neurovascular injuries $(5,35,36)$. Cases with complications needed multiple surgical interventions and led sometimes to irreversible sequela in otherwise healthy newborns $(5,32)$. More scientific papers showed during that period that long-term complications may also occur with these surgeries such as ankle stiffness, subtalar joint arthritis and residual deformity $(37,38)$. Therefore, there was growing evidence that surgery might not be the primary treatment for clubfoot and should be left for cases resistant to manipulative treatment.

In early and mid-nineties, little after Lebanon went out of the destructive civil war and retrieved stability and growth, plenty of newly formed orthopedic surgeons traveled to Europe and the United States to complete fellowships and surgical trainings. It was during that period that the concept of the calcaneopedal unit (CPU) was introduced and taught in Lebanon and in the MiddleEast region $(39,40)$. Simultaneously, the freshly graduated POS in the region, particularly in Lebanon introduced the Ponseti's technique and the French functional method for the treatment of congenital clubfoot $(17,41-43)$. Both methods were presented as attractive after witnessing recurrent failures and sub-optimal results with primary surgical treatment. They are also appealing because they spare patients surgeries, risks of anesthesia and offer them nearly an $80 \%$ success rate $(5,43-45)$. Both techniques were concordant with CPU concept, even if this was not clearly said by Ponseti. The thumb of one hand pushing against the talar head while the second hand manipulates the CPU in the opposite direction is a practical application of the CPU concept in management of clubfoot (40). With the years, and mainly after 2000s, the French functional method lost the ground in Lebanon in favor of Ponseti's method that became, by far the most adopted technique in Lebanon and the Middle East (21). This is mainly due to two flaws observed with the functional technique. First, the necessity for daily parents and therapists engagement and commitment for sometimes 6 months of age $(5,42)$. Secondly, the rising medical evidence showing the need for a subsequent posterior release for residual equinus in the French functional technique $(46,47)$.

This is how, in a five-decades period, in the Middle East and mainly in Lebanon, congenital clubfoot management went from manipulation through Kite's technique, to early surgical intervention, and then back to manipulation with Ponseti's technique and the French functional technique, with the latter falling out of favor with time (Figure 1).
Ponseti's technique in the region is associated with similar success rates as those reported in the medical literature (21).

\section{Survey to assess common practice in POS from the Middle East}

\section{Construction of the questionnaire}

As there is not enough published data on the management of the clubfoot deformity in the Middle East, we decided to perform a survey evaluating the common practice in clubfoot management of POS of the Middle East. A set of questions was prepared, reviewed and verified by the investigators. It included questions about the participant and his experience in the field of pediatric orthopedic surgery, about the strategy he follows to treat congenital clubfoot and the strategy he follows in case of failure or relapse after initial treatment. The questionnaire is annexed to the manuscript (Annex 1). The survey was web-based using Google forms (Google LLC, California). Trial runs were internally conducted among four consultants in our department to check the clarity of questions and the non-ambiguity of the provided options. These consultants and experts met with general orthopedic surgeons, pediatricians and caregivers of patients with clubfeet and evaluated to content and face validity of the survey. This is the first survey of its kind in the available literature so external validity could not be assessed. Internal validity through Cronbach coefficient was not performed as results were expected to be unstable as this survey targets specific specialists and having 300 to 500 responders to evaluate internal validity was impossible. The survey was approved by our institutional review board.

Middle East countries include Lebanon, Syria, Iraq, Jordan, Kingdom of Saudi Arabia, Kuwait, Qatar, Bahrein, United Arab Emirates, Oman and Yemen. The list of members of the Middle East Pediatric Orthopedic Society (MEPOS) was requested. The e-mail contacts of the POS were collected and used to send them a web link to the questionnaire. Invitation e-mails were signed by the two authors of this paper. Two reminders were sent 1 month interval. Data collection was stopped 1 month after the last reminder. The collected data was exported in a Microsoft excel file and was scanned for incomplete and duplicate responses before proceeding to analysis. No incentives were presented to participants.

\section{Analysis of collected data}

Only descriptive analysis of data is performed. There was 


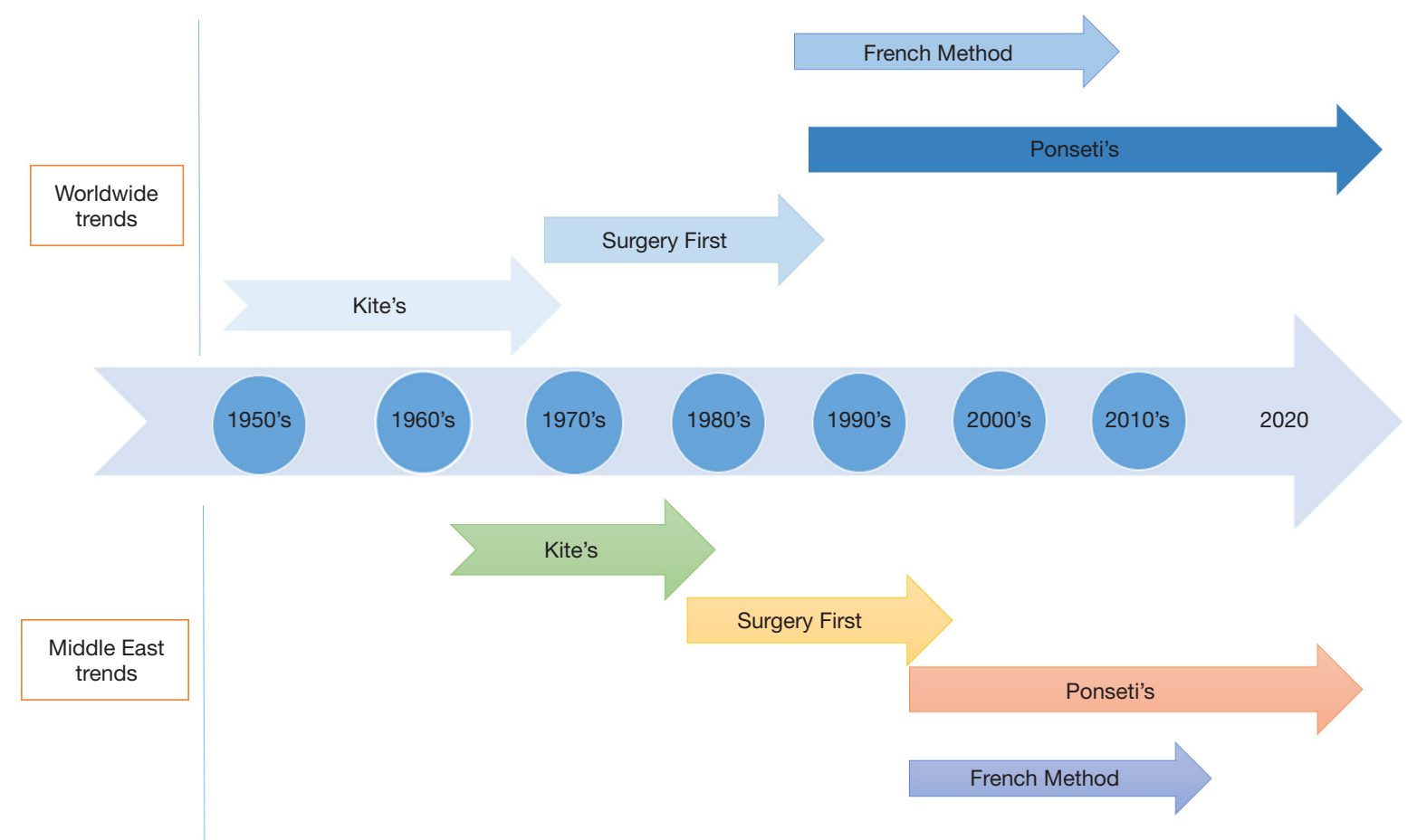

Figure 1 Timeline comparing the main trends in the treatment of congenital clubfoot in the world to those in the Middle East.

no missing data in the surveys filled by the responders. Non-responders were all male POS. Demographic data of non-responders was not analyzed due to lack of information in the MEPOS data base.

\section{Participant's practice}

Out of 55 registered POS, 34 responded (61.81\%). All respondents were male POS (100\%). Fourteen (41.17\%) practice in Lebanon, 13 (38.24\%) practice in Egypt, 2 (5.88\%) practice in Syria, 2 (5.88\%) practice in UAE and 1 (2.94\%) surgeon practices in each of Iraq, Qatar and Oman. Five (14.7\%) POS were aged between 30 and 40, 5 (14.7\%) between 40 and 50, 15 (44.1\%) between 50 and 60 and 9 (26.5\%) between 60 and 70 . No respondents were more than 70 years old. Twenty-nine (85.29\%) POS performed fellowships or specialized surgical training abroad, mainly in France (12 POS, 35.29\%), USA (8 POS, 23.53\%) and the UK (5 POS, $14.71 \%$ ). In $56 \%$ of cases, only POS take care of clubfeet in the hospitals where they practice, whereas in $41 \%$ of cases, general orthopedic surgeons manage clubfeet also. Around 70\% of respondents treat more than 20 patients with clubfoot deformity per year, with more than $80 \%$ having $>10$ years' experience in clubfoot treatment.

\section{Clubfoot screening}

In $55.9 \%$ of cases, clubfeet are rarely/never diagnosed on regular follow-up obstetrical ultrasound. Clubfoot screening is common only in $20.6 \%$ of cases (Figure 2). Thirtyone $(91.2 \%)$ responders look systematically for associated conditions to rule out a syndromic clubfoot.

\section{Preferred method of treatment}

The first line treatment for idiopathic clubfoot in $97.1 \%$ of cases [33/34] is the Ponseti method of serial manipulations and casting. All respondents prefer to start treatment soon after birth when this is possible. During their career, $61.8 \%$ of POS [21] shifted their first line treatment from a method to another. This happened because of sub-optimal results witnessed with the initial method they used $(50 \%)$ or because of growing scientific evidence favoring the Ponseti's technique $(50 \%)$. The majority of POS got familiar with this technique either through training in a department where this is the regular technique $(48.5 \%)$ or through conferences, books, and journals (36.4\%).

Answers were divergent regarding the upper age limit of manipulation and casting as $9.1 \%$ of POS fixed this age at 


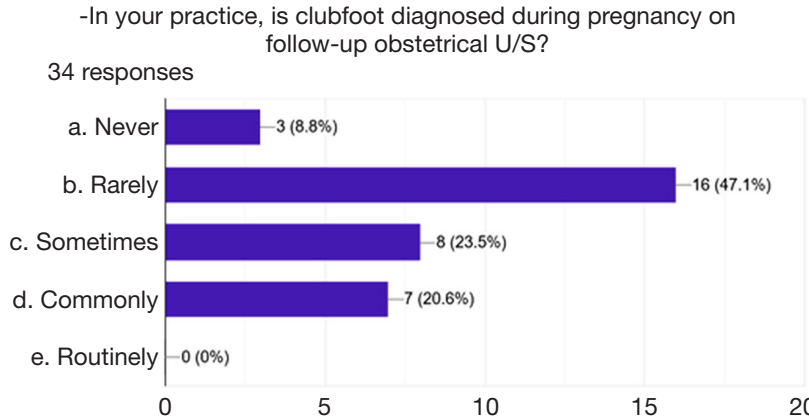

Figure 2 Chart showing the repartition of answers from the survey to the question concerning common practice in the middle-east concerning screening for clubfoot deformity during pregnancy. U/ S, ultrasound.

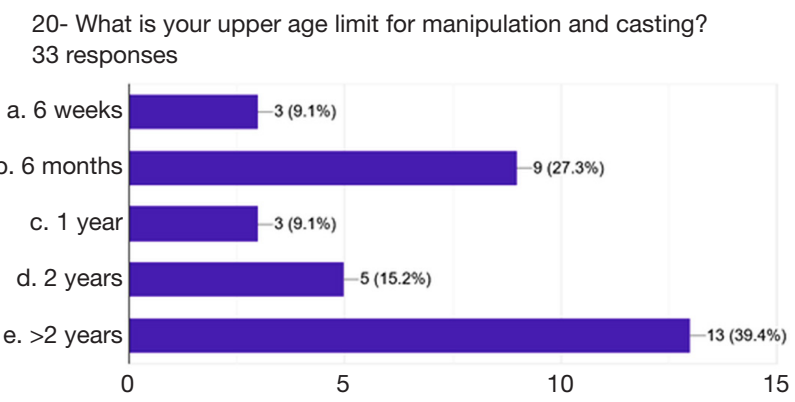

Figure 3 Chart showing the repartition of answers from the survey to the question concerning the upper age limit for manipulation and casting.

6 weeks, $27.3 \%$ fixed it at 6 months, $9.1 \%$ fixed it at 1 year, $15.2 \%$ at 2 years and $39.4 \%$ above 2 years of age (Figure 3). The majority of POS (63.6\%) perform some manipulation before casting. All respondents perform the casting in a casting room without anesthesia and put an above knee cast with a flexed knee as per the Ponseti's technique, whereas two thirds $(66.67 \%)$ perform Achilles tenotomy in $>95 \%$ of cases. Achilles tenotomy is performed percutaneously in the office with local anesthesia by $68.8 \%$ of respondents whereas $30 \%$ of respondents do an open Achilles tenotomy in the operating room. The vast majority of respondents perform the tenotomy 1 to 2 casts before the end of the treatment. Around $50 \%$ of POS use 5 to 7 casts for treatment. Half of the respondents base their thinking on the CPU concept.

\section{Preferred method in case of failure of the primary chosen approach}

The majority of respondents (91.2\%) perform surgery as a treatment for clubfoot in children older than 1.5 years mainly after failure of a previous conservative method. In this case, $60 \%$ of respondents prefer Turco approach whereas $30 \%$ prefer the Cincinnati approach.

\section{Follow-up after the initial treatment}

While $58.82 \%$ of POS assess the results of their treatment only clinically through physical exam, $41.17 \%$ assess the results of the treatment clinically and radiographically through X-ray. All respondents use day/night orthosis after completion of treatment, mainly the Denis-Brown device, day and night till walking age then only by night till the age of 4 years $(73.52 \%)$. For the follow-up, 28 of the $34(82.35 \%)$ respondents follow-up their patients clinically and radiographically with an X-ray every 6 months for 2 years then every 2 years till the end of the growth. About $75 \%$ of respondents judge the compliance of parents and children to orthosis as good or perfect. Twenty-five out of 34 respondents $(73.53 \%)$ judge the success rate of the treatment they perform as superior to $75 \%$. Main complications observed were sustained equinus, dynamic supination and relapse of deformity.

\section{Discussion}

The aim of this review was to summarize the evolution of clubfoot management in the Middle East. Since there is really sparse data concerning this, we conducted a survey among POS in the region in order to have objective answers to most frequently asked questions related to the topic.

The review of the treatment evolution through the last decades in the Middle East shows that it followed the American and the European evolutions $(5,10,32,43)$. As the timeline shows, there were a delay of about 15 years in treatment adoption in the beginning (Figure 1). However, starting late nineties of the last century the delay in treatment adoption was reduced with information diffusion through internet, the ease of access to scientific data, the increased participation in the international congresses and the increased numbers of fellows from Middle East, particularly from Lebanon visiting the specialized training centers in the USA and in Europe (Figure 1). This made Middle East up to date with the management of clubfoot, as shown by the adoption of Ponseti's conservative clubfoot management since the last decade, which is now the worldwide gold standard of congenital clubfoot management $(13,48)$. We believe that the evolution of management in 
the Middle East region witnessed a turning point with the progressive acceptance of the CPU concept (39). Ponseti used the talar head as a fulcrum for correction thereby adopting the CPU concept without clearly describing it as such (40). He clearly spoke about "Kite's error" who tried to perform the correction using the calcaneocuboid joint as a fulcrum, accounting for the high rate of failure witnessed when applying his technique (21). We believe that the CPU concept understanding and adoption in Lebanon and the Middle East made the adoption of the Ponseti and of the French functional methods smooth and quick.

However, this review of management in the Middle East through the last decades was based on the authors witnessed experience as young medical students, orthopedic surgery residents, fellows, and later-on specialized orthopedic surgeons as no data is available in the literature concerning this subject in the Middle East. The survey used for the purpose of this chapter gave the authors objective data about how clubfoot is currently managed in the Middle East.

We believe that the recorded response rate of $61.81 \%$ is satisfying and representative of the addressed sample (49). The main findings in the characteristics of respondents are the male preponderance $(100 \%)$ representative of the high male predominance in the domain of surgery mainly in the Middle East. The majority of respondents are from Lebanon since this country was among the firsts in the Middle East to send fellows to Europe and the United States to perform specialized training in different domains of orthopedic surgery (pediatrics, spine surgery, oncology, complex reconstructions). Another finding worth commenting is the high rate of POS receiving their specialized surgical training abroad underlining the role of France, the USA and the UK as role model poles for super specialized surgery training.

The adherence to the Ponseti's treatment technique is overwhelming being the preferred method for $97.1 \%$ of respondents, with more than half of these having adopted another technique before shifting to Ponseti's manipulation and casting. This is accountable to the fact that $70.6 \%$ of the respondents are above 50 years old and have therefore passed through the evolution of management of clubfoot in the Middle East discussed in the second section of this manuscript.

Despite the general agreement observed on the necessity of starting the treatment as soon as possible, together with the necessity of performing the Achilles tenotomy in the majority of cases, mainly 1 to 2 casts before the end of the treatment, divergence was observed regarding the upper age limit for manipulation and casting and the suitable setting for the Achilles tenotomy, whether it is in the outpatient clinic or in the operating room. Both these subjects are still controversial in the literature as the upper limit of age for proposing a primary Ponseti treatment remains a moving target, and many papers in the literature fail to show superiority of a technique over the other (clinics $v s$. operating room for tenotomy) $(5,50,51)$.

Respondents agreed however on the after-cast followup, encountered the same complications and had the same issues with parents and children noncompliance. One more agreement between respondents was found on the need for surgery after failed conservative treatment.

Of note, there is a lack of prenatal screening for clubfoot in the Middle East as witnessed by the response of the POS, who are expected to be working in tertiary referral centers in their respective countries. Raising awareness about clubfeet among our colleagues gynecologists in the Middle East is still needed, especially that screening for clubfoot and possible associated conditions is feasible $(4,52,53)$. Available evidence suggests that false positive rate can be lowered to around $10 \%$ if the diagnosis is performed in the second trimester $(54,55)$. This is of paramount importance as parents can be prepared for the diagnosis, and counselled for the disease, the presence (or not) of associated conditions and the path of the treatment, before birth of their awaited child $(54,56)$. They will also be oriented to seek care as soon as possible after birth increasing the chance of presenting optimal care for their children $(52,53,56)$. Much work is still to do on these aspects as people awareness on this condition is very poor (33).

In conclusion, the worldwide gold standard approach for management of congenital clubfoot is now widely accepted among POS in the Middle East. Newborns with this common condition are receiving the most adequate treatment supported by the strongest available evidence. The disagreements between POS were only found in subjects that are still a matter of debate in the international scientific community with no evidence-based clear answer (whether to perform the Achilles tenotomy in the clinics or in the operating room, and the upper limit of age for performance of Ponseti's serial casting, which is still a matter of debate and a moving target).

We are aware that the list of 55 POS in the Middle East may not be exhaustive as there may be trained POS specialists exercising in their respective country without being registered in the MEPOS. More, we are aware 
also that clubfoot is being treated by general orthopedic surgeons, especially in rural areas in the Middle East. However, even though this may not be truly representative of the clubfoot management in each and every corner of the Middle East, it still gives a clear idea about the dynamics of management and the approach used to treat this disease in the main referral hospitals in our region.

\section{Acknowledgments}

Acknowledgments to all pediatric orthopedic surgeons in the Middle East who participated in the survey.

Funding: None.

\section{Footnote}

Provenance and Peer Review: This article was commissioned by the Guest Editors (Federico Canavese and Alain Dimeglio) for the series "Clubfoot" published in Annals of Translational Medicine. The article has undergone external peer review.

Reporting Checklist: The authors have completed the SURGE reporting checklist. Available at http://dx.doi. org/10.21037/atm-21-33

Conflicts of Interest: Both authors have completed the ICMJE uniform disclosure form (available at http://dx.doi. org/10.21037/atm-21-33). The series "Clubfoot" was commissioned by the editorial office without any funding or sponsorship. The authors have no other conflicts of interest to declare.

Ethical Statement: The authors are accountable for all aspects of the work in ensuring that questions related to the accuracy or integrity of any part of the work are appropriately investigated and resolved.

Open Access Statement: This is an Open Access article distributed in accordance with the Creative Commons Attribution-NonCommercial-NoDerivs 4.0 International License (CC BY-NC-ND 4.0), which permits the noncommercial replication and distribution of the article with the strict proviso that no changes or edits are made and the original work is properly cited (including links to both the formal publication through the relevant DOI and the license). See: https://creativecommons.org/licenses/by-nc$\mathrm{nd} / 4.0 /$.

\section{References}

1. Barrie A, Varacallo M. Clubfoot. Treasure Island (FL): StatPearls Publishing, 2020.

2. Peterson N, Prior C. Correction of the Neglected Clubfoot in the Adolescent and Adult Patient. Foot Ankle Clin 2020;25:205-20.

3. Murtaza K, Saleem Z, Malik S. Talipes equinovarus or Clubfoot: A review of study approaches, management and trends in Pakistan. PakJ Med Sci 2020;36:1414-20.

4. Yau A, Doyle SM. Clubfoot for the primary care physician: frequently asked questions. Curr Opin Pediatr 2020;32:100-6.

5. Dobbs MB, Gurnett CA. Update on Clubfoot: Etiology and Treatment. Clin Orthop Relat Res 2009;467:1146-53.

6. Wang LL, Fu WN, Li-Ling J, et al. HOXD13 may play a role in idiopathic congenital clubfoot by regulating the expression of FHL1. Cytogenet Genome Res 2008;121:189-95.

7. Wynne-Davies R. Genetic and Environmental Factors in the Etiology of Talipes Equinovarus. Clin Orthop Relat Res 1972;84:9-13.

8. Gurnett CA, Boehm S, Connolly A, et al. Impact of congenital talipes equinovarus etiology on treatment outcomes. Dev Med Child Neurol 2008;50:498-502.

9. Bakalis S, Sairam S, Homfray T, et al. Outcome of antenatally diagnosed talipes equinovarus in an unselected obstetric population. Ultrasound Obstet Gynecol 2002;20:226-9.

10. Hernigou P, Huys M, Pariat J, et al. History of clubfoot treatment, part I: From manipulation in antiquity to splint and plaster in Renaissance before tenotomy. Int Orthop 2017;41:1693-704.

11. Dobbs MB, Morcuende JA, Gurnett CA, et al. Treatment of idiopathic clubfoot: an historical review. Iowa Orthop J 2000;20:59-64.

12. Balasankar G, Luximon A, Al-Jumaily A. Current conservative management and classification of club foot: A review. J Pediatr Rehabil Med 2016;9:257-64.

13. Sanzarello I, Nanni M, Faldini C. The clubfoot over the centuries. J Pediatr Orthop B 2017;26:143-51.

14. Chu A, Lehman WB. Treatment of Idiopathic Clubfoot in the Ponseti Era and Beyond. Foot Ankle Clin 2015;20:555-62.

15. Zionts LE. What's New in Idiopathic Clubfoot? J Pediatr Orthop 2015;35:547-50.

16. Bergerault F, Fournier J, Bonnard C. Idiopathic congenital clubfoot: Initial treatment. Orthop Traumatol Surg Res 
2013;99:S150-9.

17. Ponseti IV. Treatment of congenital club foot. J Bone Joint Surg Am 1992;74:448-54.

18. Shabtai L, Specht SC, Herzenberg JE. Worldwide spread of the Ponseti method for clubfoot. World J Orthop 2014;5:585-90.

19. Pirani S, Naddumba E, Mathias R, et al. Towards effective Ponseti clubfoot care: the Uganda Sustainable Clubfoot Care Project. Clin Orthop Relat Res 2009;467:1154-63.

20. Jayawardena A, Wijayasinghe SR, Tennakoon D, et al. Early effects of a "train the trainer" approach to Ponseti method dissemination: a case study of Sri Lanka. Iowa Orthop J 2013;33:153-60.

21. Jawadi AH. Clubfoot management by the Ponseti technique in Saudi patients. Saudi Med J 2010;31:49-52.

22. Bittar Z. Major congenital malformations presenting in the first 24 hours of life in 3865 consecutive births in south of Beirut. Incidence and pattern. J Med Liban 1998;46:256-60.

23. Al-Ani ZR, Al-Haj SA, Al-Ani MM, et al. Incidence, types, geographical distribution, and risk factors of congenital anomalies in Al-Ramadi Maternity and Children's Teaching Hospital, Western Iraq. Saudi Med J 2012;33:979-89.

24. El Koumi MA, Al Banna EA, Lebda I. Pattern of congenital anomalies in newborn: a hospital-based study. Pediatr Rep 2013;5:e5.

25. Smythe T, Kuper H, Macleod D, et al. Birth prevalence of congenital talipes equinovarus in low- and middle-income countries: a systematic review and meta-analysis. Trop Med Int Health 2017;22:269-85.

26. Ansar A, Rahman AE, Romero L, et al. Systematic review and meta-analysis of global birth prevalence of clubfoot: a study protocol. BMJ Open 2018;8:e019246.

27. Kite JH. The treatment of congenital clubfeet. J Am Med Assoc 1932;99:1156.

28. Kite JH. Some suggestions on the treatment of club foot by casts. J Bone Joint Surg Am 1963;45-A:406-12.

29. Kite JH. Principles involved in the treatment of congenital club-foot. 1939. J Bone Joint Surg Am 2003;85:1847; discussion 1847.

30. Lovell WW, Farley D. Treatment of congenital clubfoot. ONA J 1979;6:453-6.

31. Aronson J, Puskarich CL. Deformity and disability from treated clubfoot. J Pediatr Orthop 1990;10:109-19.

32. Carroll NC. Clubfoot in the twentieth century. J Pediatr Orthop B 2012;21:1-6.

33. Alsiddiky A, Alrwibaah S, Alqahtani A, et al. Assessing public awareness of clubfoot and knowledge about the importance of early childhood treatment: a cross-sectional survey. BMC Pediatr 2019;19:358.

34. McKay DW. New concept of and approach to clubfoot treatment: section I-principles and morbid anatomy. J Pediatr Orthop 1982;2:347-56.

35. Kuo KN, Jansen LD. Rotatory dorsal subluxation of the navicular: a complication of clubfoot surgery. J Pediatr Orthop 1998;18:770-4.

36. Atar D, Lehman WB, Grant AD. Complications in clubfoot surgery. Orthop Rev 1991;20:233-9.

37. Dobbs MB, Nunley R, Schoenecker PL. Long-Term Follow-up of Patients with Clubfeet Treated with Extensive Soft-Tissue Release. J Bone Joint Surg Am 2006;88:986-96.

38. Ippolito E, Farsetti P, Caterini R, et al. Long-term comparative results in patients with congenital clubfoot treated with two different protocols. J Bone Joint Surg Am 2003;85:1286-94.

39. Seringe $R$, Wicart $P$. The talonavicular and subtalar joints: The "calcaneopedal unit" concept. Orthop Traumatol Surg Res 2013;99:S345-55.

40. Ghanem I, Massaad A, Assi A, et al. Understanding the foot's functional anatomy in physiological and pathological conditions: the calcaneopedal unit concept. J Child Orthop 2019;13:134-46.

41. Laaveg SJ, Ponseti IV. Long-term results of treatment of congenital club foot. J Bone Joint Surg Am 1980;62:23-31.

42. Bensahel H, Catterall A, Dimeglio A. Practical applications in idiopathic clubfoot: a retrospective multicentric study in EPOS. J Pediatr Orthop 1990;10:186-8.

43. Hernigou P. History of clubfoot treatment; part III (twentieth century): back to the future. Int Orthop 2017;41:2407-14.

44. Diméglio A, Bonnet F, Mazeau P, et al. Orthopaedic treatment and passive motion machine: consequences for the surgical treatment of clubfoot. J Pediatr Orthop B 1996;5:173-80.

45. Cooper DM, Dietz FR. Treatment of idiopathic clubfoot. A thirty-year follow-up note. J Bone Joint Surg Am 1995;77:1477-89.

46. Richards BS, Faulks S, Rathjen KE, et al. A comparison of two nonoperative methods of idiopathic clubfoot correction: the Ponseti method and the French functional (physiotherapy) method. J Bone Joint Surg Am 2008;90:2313-21.

47. Van Campenhout A, Molenaers G, Moens P, et al. Does Functional Treatment of Idiopathic Clubfoot Reduce the Indication for Surgery? Call for a Widely Accepted Rating System. J Pediatr Orthop B 2001;10:315-8. 
48. Kadhum M, Lee MH, Czernuszka J, et al. An Analysis of the Mechanical Properties of the Ponseti Method in Clubfoot Treatment. Appl Bionics Biomech 2019;2019:4308462.

49. Fincham JE. Response Rates and Responsiveness for Surveys, Standards, and the Journal. Am J Pharm Educ 2008;72:43.

50. Tuhanioğlu Ü, Oğur HU, Seyfettinoğlu F, et al. Percutaneous achillotomy in the treatment of congenital clubfoot: should it be performed in the operating theater or the polyclinic? J Orthop Surg Res 2018;13:155.

51. Agius L, Wickham A, Walker C, et al. Achilles tenotomy as an office procedure and current practising trends among New Zealand orthopaedic surgeons. N Z Med J 2018;131:44-50.

52. McKinney J, Rac MWF, Gandhi M. Congenital

Cite this article as: Ghanem I, Rizkallah M. Clubfoot management in the Middle East: a survey-based review. Ann Transl Med 2021;9(13):1106. doi: 10.21037/atm-21-33 talipes equinovarus (clubfoot). Am J Obstet Gynecol 2019;221:B10-2.

53. Mahan ST, Yazdy MM, Kasser JR, et al. Prenatal screening for clubfoot: what factors predict prenatal detection? Prenat Diagn 2014;34:389-93.

54. Lanna M, Casati D, Torre C, et al. Congenital isolated clubfoot: Correlation between prenatal assessment and postnatal degree of severity. Prenat Diagn 2020;40:1547-52.

55. Glotzbecker MP, Estroff JA, Spencer SA, et al. Prenatally diagnosed clubfeet: comparing ultrasonographic severity with objective clinical outcomes. J Pediatr Orthop 2010;30:606-11.

56. Di Mascio D, Buca D, Khalil A, et al. Outcome of isolated fetal talipes: A systematic review and meta-analysis. Acta Obstet Gynecol Scand 2019;98:1367-77. 


\section{Supplementary}

\section{Annex 1: The web-based questionnaire sent to the 55 pediatric orthopedic surgeons}

\section{Approach to congenital clubfoot treatment among pediatric orthopedic surgeons in the Middle East}

1. In which country of the Middle East do you practice pediatric orthopedics?

2. In which country/countries did you perform your surgical training?

3. How old are you?
a. $30-40$
b. $40-50$
c. $50-60$
d. $60-70$
e. $>70$

4. Gender
a. $M$
b. F

5. In your department, who takes care of clubfoot?
a. Only pediatric orthopedists
b. General orthopedists
c. Both
d. General pediatric surgeons
e. Physical therapists
f. Cast technician

6. How many clubfeet do you usually treat per year?
a. $<20$
b. $20-50$
c. $50-100$
d. $100-200$
e. $>200$

7. In your practice, is clubfoot diagnosed during pregnancy on follow-up obstetrical U/S?
a. Never
b. Rarely
c. Sometimes
d. Commonly
e. Routinely

8. Do you perform $\mathrm{AP}$ and lateral foot $\mathrm{X}$-ray at first presentation to confirm the diagnosis?
a. Never
b. When physical exam is suspicious
c. Routinely

9. Do you look for associated conditions?
a. Never
b. If there is a clinical suspicion
c. Routinely 
10. What is your first line treatment for clubfoot?
a. Ponseti method of serial manipulation and casting
b. The French functional method
c. Kite method
d. Surgery
e. Other, please specify

11. How early do you prefer to start your treatment?
a. Soon after birth
b. Age 1 month-6 months
c. Age 6 months -12 months
d. Between 12 and 24 months
e. Other, please specify

12. During your carrier, did you happen to shift from one method to the other?
a. No
b. Yes

13. If your answer to question 12 is yes, why did you do so?
a. Not enough good results with the previous method
b. Curiosity
c. New trend
d. Supported by evidence in the literature
e. Other, please specify

\section{The following questions [14-24] concern your first line treatment of clubfoot}

14. How did you get familiar with this method?
a. I worked with Ponseti/Kite/Bensahel/Turco/Mckay or one of their disciples
b. I trained in a department where this was the preferred method of clubfoot treatment
c. I got familiar with the technique from conferences, books and/or journals
d. Other, please specify

15. What is your upper age limit for manipulation and casting?
a. 6 weeks
b. 6 months
c. 1 year
d. 2 years
e. $>2$ years

16. Do you do any manipulation prior to casting?
a. Never
b. Sometimes
c. Always

17. Where do you do your casting?
a. Cast room without anesthesia
b. Cast room with sedation
c. Operating room with sedation or anesthesia
d. Other, please specify 
18. Is your cast:
a. Above knee with knee flexed
b. Above knee with knee extended
c. Below knee
d. Variable, please specify

19. Usually, what is your average number of casts?
a. $<5$
b. $5-7$
c. $7-9$
d. $>9$

20. How often do you base your correction on the calcaneopedal unit concept?
a. Never
b. Sometimes
c. Always
d. Never heard of this concept

21. How often do you perform Achilles tenotomy?
a. Never
b. $<10 \%$
c. $10-40 \%$
d. $40-70 \%$
e. $>95 \%$

22. How do you perform the Achilles tendon tenotomy?
a. Percutaneous complete tenotomy using a knife
b. Percutaneous complete tenotomy using a needle
c. Percutaneous lengthening according to Green or Hook
d. Open tenotomy
e. Open lengthening

23. When do you perform the Achilles tendon tenotomy?
a. At first cast
b. During the course of casting
c. 1-2 casts before the end of casting
d. Other, please specify

24. Where do you perform the Achilles tendon tenotomy?
a. Cast room without local anesthesia
b. Cast room with local anesthesia
c. Operating room under anesthesia or sedation
d. Other, please specify 


\section{The following questions [25-30] concern surgery as a treatment for clubfoot}

25. Why would you do surgery for clubfoot treatment?
a. I was trained more on surgical management
b. I believe more in surgery than in conservative management
c. I am not familiar with casting or the French method
d. I don't see children early enough to start conservative management
e. I do surgery in children older than 1.5-2 years only, mainly after failure of previous conservative methods

26. What is your preferred age for surgery?
a. $6-12$ months
b. $12-18$ months
c. $18-24$ months
d. Other, please specify

27. What is your preferred surgical approach?
a. Turco
b. Seringe
c. Cincinnati
d. Other, please specify

28. How often do you perform bony procedures in addition to standard posteromedial release?
a. Never
b. In severe clubfeet
c. In relapsed clubfeet
d. In old children and adolescents
e. Very often

29. How often do you use serial casting prior to surgery in severe clubfeet?
a. Never
b. In old children and adolescents
c. In relapsed clubfeet
d. Very often

30. How often do you apply external fixation for gradual correction?
a. Never
b. In severe clubfoot after the age of 3 years
c. In neglected clubfoot in old children and adolescents
d. In relapsed severe clubfeet
e. Other, please specify

31. How do you assess the result of treatment?
a. Clinically
b. Radiographically
c. Ultrasound
d. Other, please specify 
32. Do you use any day/night orthosis after completion of treatment?
a. Never
b. Sometimes, please specify
c. Always

33. If your answer to question 32 is b or c, what type of orthosis do you use after conservative treatment, and for how long?
a. Dennis Brown day and night till walking age, then only night till age 4 years
b. Mitchell boots day and night till walking age, then only night till age 4 years
c. Either one till walking age, then night AFO till age 4 years
d. Day and night AFO till walking age, then night AFO till age 4 years
e. Other, please specify

34. If your answer to question 32 is b or c, what type of brace do you use after surgical treatment, and for how long?
a. Dennis Brown or Mitchell boots day and night for 2 years
b. AFO day and night for 2 years
c. Either one during the day for 6 months, then at night for 2 years
d. Other, please specify

35. How do you follow-up on your patient?
a. Clinically and radiologically every 6 months for 2 years then every year or 2 years till the end of growth
b. Clinically and Ultrasound/MRI
c. Other, please specify

36. What is your general impression regarding parental/patient compliance to orthosis after initial treatment?
a. Poor
b. Fair
c. Good
d. Perfect

37. In your experience what is the rate of the success of treatment with conservative methods?
a. $<50 \%$
b. $50-75 \%$
c. $75-95 \%$
d. $>95 \%$

38. What are the main complications that you encountered following conservative treatment?
a. Relapse of deformity
b. Dynamic supination
c. Persistent equinus
d. Rocker bottom deformity
e. Overcorrection

39. What do you propose for neglected clubfoot presenting after $2-3$ years of age?
a. Trial of conservative management
b. Standard posteromedial release
c. Medial column lengthening and lateral column shortening
d. Talectomy
e. Multiplanar supra-malleolar osteotomy
f. Gradual correction with ring external fixator
g. Other, please specify 